\title{
Review of Euratom projects on design, safety assessment, R\&D and licensing for ESNII/Gen-IV fast neutron systems
}

\author{
Konstantin Mikityuk ${ }^{1, *}$, Luca Ammirabile ${ }^{2}$, Massimo Forni ${ }^{3}$, Jacek Jagielski ${ }^{4}$, Nathalie Girault ${ }^{5}$, \\ Akos Horvath $^{6}$, Jan-Leen Kloosterman ${ }^{7}$, Mariano Tarantino ${ }^{8}$, and Alfredo Vasile ${ }^{9}$ \\ 1 PSI, Forschungsstrasse 111, 5232 Villigen PSI, Switzerland \\ 2 JRC, Westerduinweg 3, 1755 LE Petten, The Netherlands \\ 3 ENEA, Via Martiri di Monte Sole, 4, 40129 Bologna, Italy \\ 4 NCBJ, A. Soltana 7, 05-400 Otwock/Swierk, Poland \\ ${ }^{5}$ IRSN, 13115 St-Paul-lez-Durance, France \\ ${ }^{6}$ MTA EK, Konkoly Thege M. út 29-33, 1121 Budapest, Hungary \\ 7 TU DELFT, Mekelweg 15, 2629 JB Delft, The Netherlands \\ 8 ENEA, FSN-ING, C.R. Brasimone, 40032 Camugnano, Italy \\ ${ }^{9}$ CEA, 13115 St-Paul-lez-Durance, France
}

Received: 12 March 2019 / Accepted: 4 June 2019

\begin{abstract}
Nine Euratom projects started since late 2011 in support of the infrastructure and R\&D of the seven fast reactor systems are briefly presented in the paper in terms of key objectives, results and recommendations.
\end{abstract}

\section{Introduction}

In November 2010 Sustainable Nuclear Energy Technology Platform (SNETP) set up a Task Force comprising research organisations and industrial partners to develop the European Sustainable Nuclear Industrial Initiative (ESNII) addressing the need for demonstration of Generation-IV Fast Neutron Reactor technologies, together with the supporting research infrastructures, fuel facilities and research and development (R\&D) work.

SNETP has prioritised the different Generation-IV systems and is proposing to develop the following projects: the sodium-cooled fast neutron reactor technology ASTRID as the reference solution; the lead-cooled fast reactor ALFRED supported by a lead-bismuth irradiation facility project MYRRHA as a first alternative; the gascooled fast reactor ALLEGRO as a second alternative. The Molten Salt Fast Reactor (MSFR) is considered as a very attractive long-term option.

The EU framework programs have supported the R\&D activities on these five systems as well as on two other Generation-IV technologies: European Sodium Fast Reactor (ESFR) and Swedish Advanced Lead Reactor (SEALER). All seven fast neutron systems are presented in Figure 1.

\footnotetext{
* e-mail: konstantin.mikityuk@psi.ch
}

The paper briefly presents in terms of key objectives, results and recommendations nine Euratom projects started since late 2011 in support of the infrastructure and $R \& D$ of the seven fast reactor systems presented above (see Fig. 1). Table 1 presents the list of the project acronyms, participants and coordinators. Figure 2 presents domains and categories of advanced systems, while Table 2 gives more details about the $R \& D$ areas. Finally, Figure 3 presents the budgets and time spans of the presented projects.

\section{SARGEN IV: Proposal for a harmonized European methodology for the safety assessment of innovative reactors with fast neutron spectrum planned to be built in Europe}

\subsection{Key objectives}

The safety of innovative reactors needs to be addressed in a comprehensive and robust manner while demonstrating a level of safety acceptable for the general public. Having a European consensus on the methodology and safety criteria that will be used to assess innovative reactors becomes of prime importance with an impact on any further design activities. 


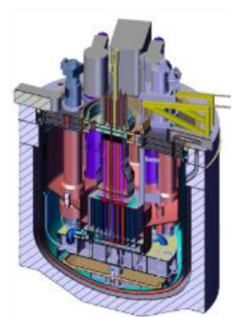

a)

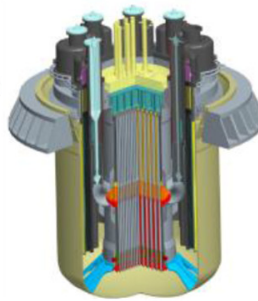

b)

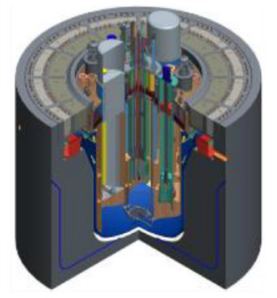

c)

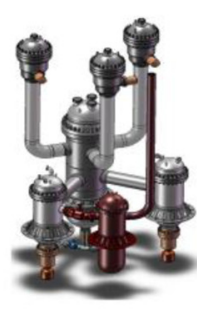

d)

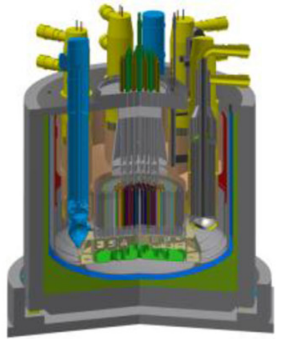

e)

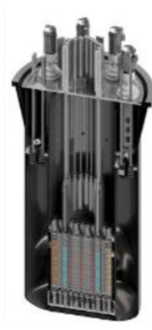

f)

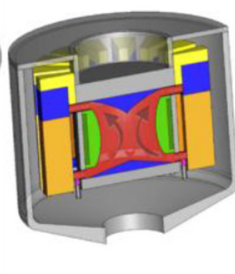

g)

Fig. 1. Seven fast neutron systems supported by the considered EU project: ASTRID (a); ALFRED (b); MYRRHA (c); ALLEGRO (d); ESFR (e); SEALER (f); MSFR (g).

Table 1. Participants and coordinators of the considered EU projects.

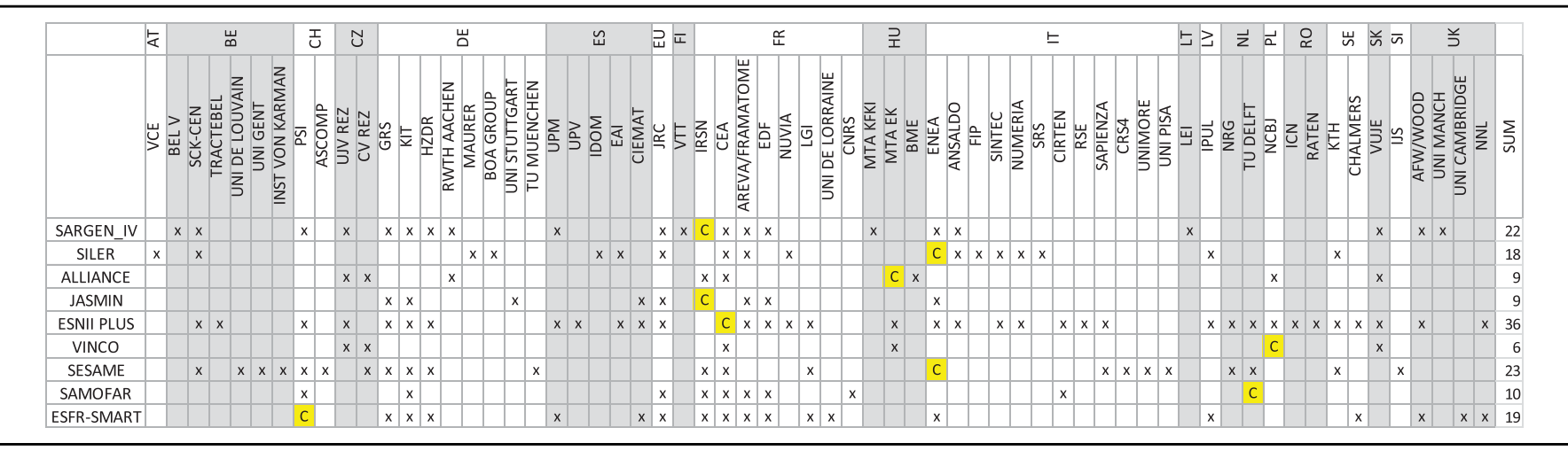

\begin{tabular}{|c|c|c|c|c|c|}
\hline & SFR & LFR & ADS & GFR & MSR \\
\hline Design & & & & & \\
\hline$R \& D$ & 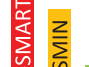 & & & 불 & 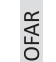 \\
\hline Safety & 5 & & & 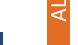 & $\sim$ \\
\hline Licensing & & & & & \\
\hline
\end{tabular}

Fig. 2. Domains and advanced systems of interests of the considered EU project.

With the goal of preparing the future assessment of these advanced reactor concepts, the European project SARGEN IV gathered safety experts from 22 partners from $12 \mathrm{E} \overline{\mathrm{U}}$ Member States: recognized European Technical Safety Organizations (TSOs), the Joint Research Centre of the EC, Designers and Vendors as well as from Research Institutes and Universities in order to:

- identify the critical safety features of the selected Generation-IV concepts, relying on the outcomes from existing projects from the 7th Framework Programme (FP7);

- develop and provide a tentative commonly agreed methodology for the safety assessment, relying on the outcomes of the investigations carried out within international organizations (such as IAEA, WENRA, $\mathrm{OECD} / \mathrm{NEA}$ ), on national practices presently in use and on practices proposed within other European Framework Programs projects;

- identify open issues in the safety area, mainly addressing and focusing on assessment relevant ones, detect and underline new fields for $R \& D$ in the safety area (addressing methodological, theoretical and experimental issues, as well) in order to provide a roadmap and preliminary deployment plan for the fast reactor safetyrelated $R \& D$.

The project partners were convinced that fostering the harmonization of the various European safety approaches would have been very beneficial and would have streamlined Euratom contribution to Generation-IV International Forum in the safety field. It was also meant to improve relationship between safety assessment needs and research programmes efficiency in the development of new concepts.

A particular attention was addressed to take into account the lessons learned from the Fukushima-Daiichi nuclear accident that will impact significantly the research and development needed for demonstration of Generation-IV reactor safety.

\subsection{Key results}

\subsubsection{WP2: identification of the major safety features}

In the project, a review on the safety issues was performed for each ESNII concept: SFR, LFR, GFR and MYRRHA 
Table 2. R\&D areas of the considered EU project.

\begin{tabular}{llllll}
\hline & TH \& CFD & Neutronics & Fuel & Seismic & Multiphysics \\
\hline SILER & & & & $\mathrm{x}$ & \\
ALLIANCE & $\mathrm{x}$ & $\mathrm{x}$ & & & $\mathrm{x}$ \\
JASMIN & $\mathrm{x}$ & $\mathrm{x}$ & $\mathrm{x}$ & $\mathrm{x}$ & $\mathrm{x}$ \\
ESNII Plus & $\mathrm{x}$ & $\mathrm{x}$ & & & $\mathrm{x}$ \\
VINCO & $\mathrm{x}$ & & & $\mathrm{x}$ \\
SESAME & $\mathrm{x}$ & $\mathrm{x}$ & $\mathrm{x}$ & \\
SAMOFAR & $\mathrm{x}$ & $\mathrm{x}$ & $\mathrm{x}$ & & \\
ESFR-SMART & $\mathrm{y}$ & & & & \\
\hline
\end{tabular}

Focus of SARGEN_IV project is safety assessment

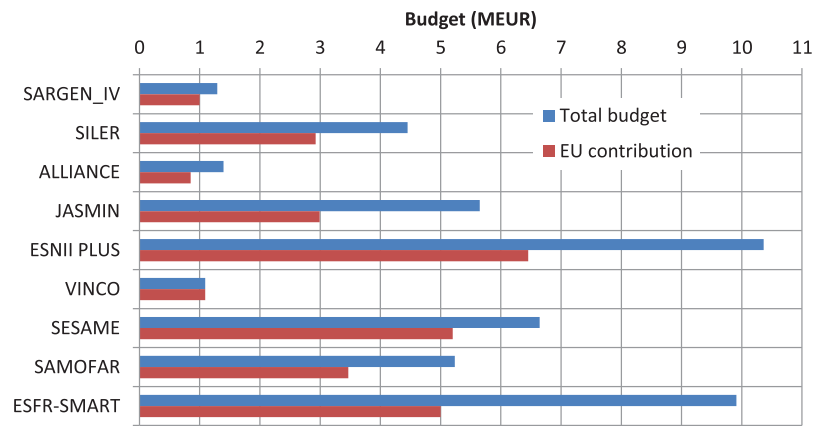

a)

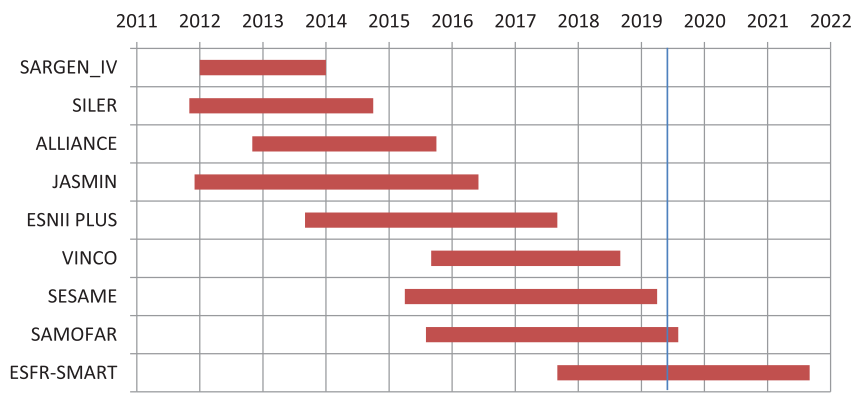

b)

Fig. 3. Budget (a) and time span (b) of the considered EU project.

FASTEF. A list of the initiating events was also identified and categorised according to their occurrence frequency.

A conclusive deliverable [1] gathered the main results for each of the three concepts and a focus was performed to identify phenomena able to affect more than one concept, i.e.

- for the coolant: sensitivity to impurities, coolant activity, retention of fissions products, toxicity, opacity;

- for the structural materials: corrosion, erosion, irradiation behaviour;

- issues in relation with fast reactors: sensitivity to blockage, power density, core compaction, reactivity void effects, handling hazards, failure of the core supporting structures;

- management of the three safety functions (reactivity control, decay heat removal, containment);

- capability to cool the core by natural circulation;

- sensitivity to external events (flooding, earthquake);

- considerations on the Fukushima-Daiichi TEPCO events (extreme flooding, extreme earthquake, total loss of electric supply, accident management);

- categorisation of initiating event organised by challenges: challenge to clad integrity, challenge to reactor boundary, containment challenge.

This work gave a useful guidance for the identification and the prioritisation of the $\mathrm{R} \& \mathrm{D}$ needs respective to the identified safety issues. In particular it was pointed out that efforts have to be performed to define the severe accident for each concept and to develop requirements for the containment in order to practically eliminate large and early releases.

\subsubsection{Develop and provide a tentative commonly agreed methodology for the safety assessment}

In the scope of the development and the licensing of the above mentioned ESNII prototypes in Europe, it appeared crucial to develop a tentative commonly agreed assessment methodology able to be applied to each of the four above mentioned concepts and based on the safety issues identified.

Firstly, it performed a review of the safety methodologies proposed by international organizations and those issued from national practices and European consortia. This included:

- INPRO methodology proposed by IAEA and ISAM proposed by the GIF;

- experience feedback for safety assessment from national TSOs approaches (from Finland, France, Belgium, Spain, Germany);

- safety approach proposed for European projects related to gas cooled, lead cooled and sodium cooled fast reactors; - safety approach proposed by international organisations (IAEA, WENRA, NEA/MDEP). 


\subsection{Recommendations for the future}

On the basis of the reviews mentioned above that led to numerous recommendations, the SARGEN_IV consortium prepared a proposal [2] for the safety assessment practices targeting the Generation-IV prototypes to be built in Europe. follows:

Some of the most important recommendations are as

- the safety assessment should cover the whole nuclear plant (reactor, fresh and spent fuel storage);

- the entire life on the plant (from commissioning to decommissioning) should be addressed;

- safety assessment should integrate the security/safeguards aspects;

- the consequences of chemical releases have to be taken into account in the design;

- the defence-in-depth (DiD) principle remains a fundamental principle for the safety of innovative reactors and an important topic is to define accurately the level 4 of DiD for each concept;

- accident sequences that could lead to large or early releases have to be practically eliminated.

\section{SILER: Seismic-Initiated Events Risk Mitigation in Lead-cooled Reactors}

SILER is a collaborative project, partially funded by the European Commission in the 7th Framework Programme, aimed at studying the risk associated with seismic-initiated events in Generation-IV Heavy Liquid Metal reactors, and developing adequate protection measures. The attention of SILER is focused on the evaluation of the effects of earthquakes, with particular regards to beyond-design seismic events, and to the identification of mitigation strategies, acting both on structures and components design. Special efforts are devoted to the development of seismic isolation devices and related interface components.

Two reference designs, at the state of development available at the beginning of the project and coming from the 6th Framework Programme, have been considered: ELSY (European Lead Fast Reactor) for the Lead Fast Reactors (LFR), and MYRRHA (Multi-purpose hYbrid Research Reactor for High-tech Applications) for the Accelerator-Driven Systems (ADS).

\subsection{Key objectives}

One of the main goals of SILER was the development and experimental qualification of seismic isolators for leadcooled reactors (but applicable to any other nuclear plant).

\subsection{Key results}

Two device typologies have been considered: High Damping Rubber Bearings (HDRBs) and Lead Rubber Bearings (LRBs). Both isolators have been designed (for ELSY and MYRRHA, respectively), manufactured and tested in different sizes, even to the full scale, which results to be greater than one meter, due to the huge mass of the reactor buildings. In particular, a prototype has been subjected to three-directional dynamic tests (at the Department of Structural Engineering of the San Diego University) under the real service loads up to failure, which occurred well beyond the design conditions.

The adoption of base isolation provides a great reduction of the acceleration and inertial forces in the structure, providing very important benefits to the components and the structure itself, but introduces significant relative displacements between the isolated and conventionally founded parts of the plant. Thus, a seismic gap of suitable width shall surround the entire isolated "island". Of course, it shall be adequately protected from bad weather (included floods) and other possible damages, and kept free during the whole life of the structure, in order to allow for relative movements in case of earthquake. Moreover, all the service networks and pipelines crossing the seismic gap shall be provided with suitable expansion joints. In SILER, both devices have been developed and successfully tested in full scale and in real operational conditions, even beyond the design limit (see Figs. 4-6). It is worth noting that, due the severe seismic condition assumed in the design of nuclear plants, the relative displacement can reach $0.7-0.8 \mathrm{~m}$ in beyonddesign situations.

In SILER, several critical components of ELSY and MYRRHA (like vessel, pumps, proton beam, etc.) have been numerically modelled and carefully analysed under severe seismic conditions, taking also into account the effects of the sloshing of the liquid lead and the soilstructure interaction.

Particular attention has been devoted to the costbenefit analysis related to the adoption of seismic isolation, which resulted to be positive. Moreover, according to the indication of EC, the main results of the project have been disseminated through the organization of seminars, courses, workshops and the implementation of a web site (http://www.siler.eu).

\subsection{Recommendations for the future}

In particular, guidelines for design, manufacturing, qualification, installation and maintenance of seismic isolators for nuclear plants have been delivered. This document is particularly important, due to the lack of international rules regarding the seismic isolation of nuclear plants (at the time of the project at least).

More information about the SILER Project main results can be founded in references $[3,4]$.

\section{ALLIANCE: Preparation of ALLEGRO - implementing advanced nuclear fuel cycle in central Europe}

Gas cooled fast reactors (GFR) represent one of the three European candidate fast reactor types, the two other being sodium cooled fast reactor (SFR) and lead cooled fast reactor (LFR). Technically, GFR is a realistic and promising complementary option thanks to its specific 


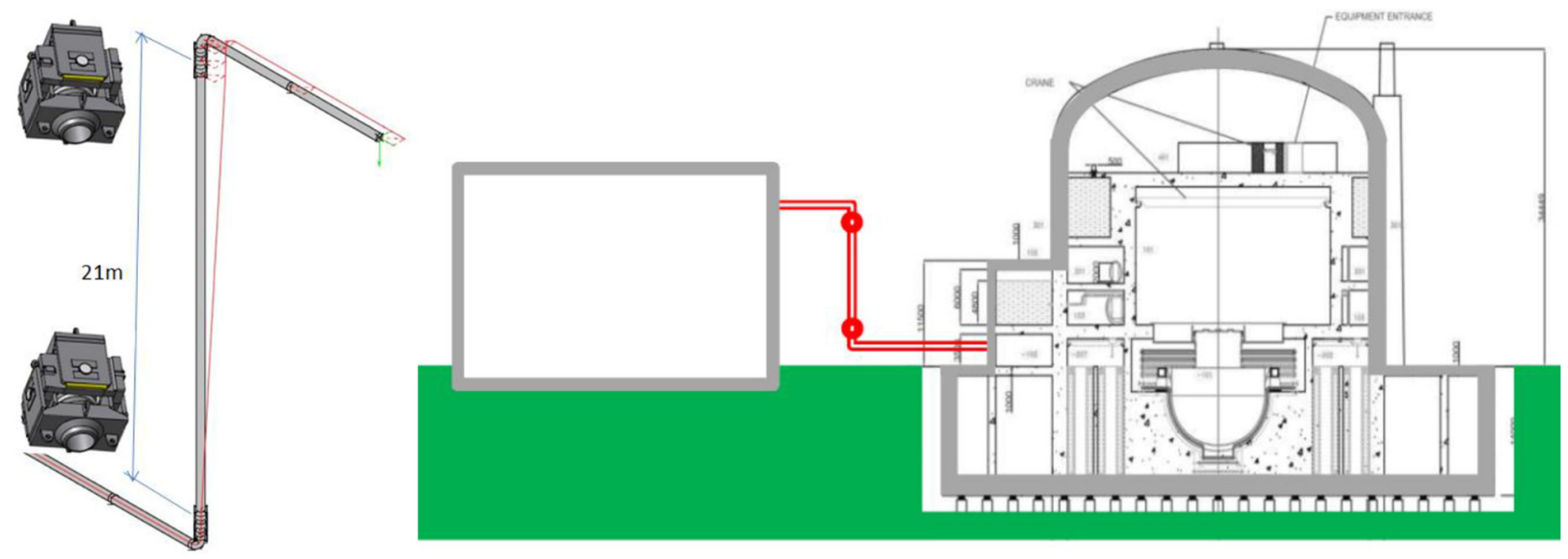

Fig. 4. Sketch of the pipeline connecting the seismically isolated reactor building of ELSY and the turbine, provided with two flexible joints to adjust the relative displacements.

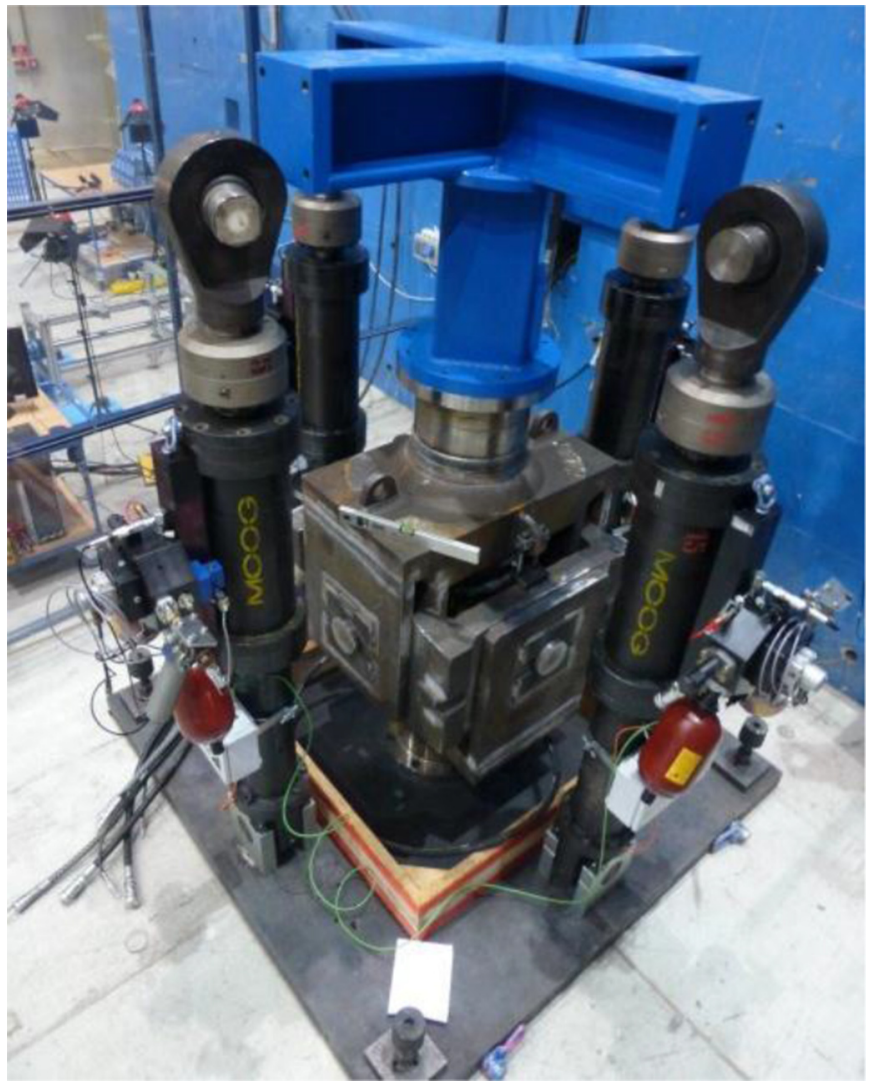

Fig. 5. Full scale pipeline expansion joint during seismic tests at the ELSA laboratory of the JRC of Ispra.

advantages connected with high temperatures. The GFR concept was mainly based on studies performed in France in the late 1990s and was further developed within the EU 5th and 6th Framework Programmes, respectively. It also included the development and safety assessment of a small experimental plant called at the time ETDR (Experimental Technology Demonstration Reactor). This plant was regarded as a necessary stepping-stone to a full-sized GFR

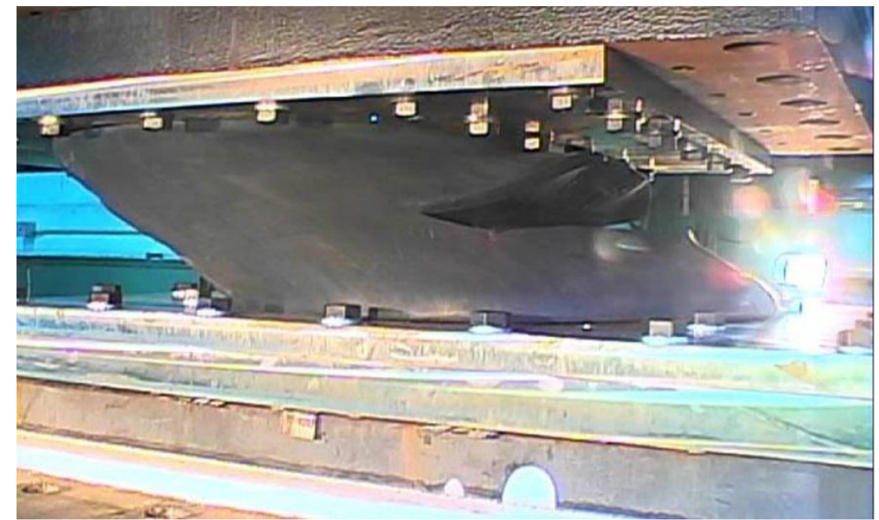

Fig. 6. Three-directional dynamic test performed at SRMD on a full-scale (1350 mm diameter) HDRB. After partial damage occurred close to $300 \%$ shear strain (almost three times the design value), the isolator was successfully subjected to a full cycle under the design load at the design conditions.

in order to test the high-temperature fuel required by the latter. The concept was further analysed and refined by the EU FP7 GoFastR project: the ETDR has been renamed ALLEGRO (see Fig. 8) and a number of design changes were introduced, e.g. the power was raised from the original $50 \mathrm{MW}$ th to $75 \mathrm{MWth}$. ALLEGRO would function not only as a demonstration reactor hosting GFR technological experiments, but also as a test pad of using the high temperature coolant of the reactor in a heat exchanger for generating process heat for industrial applications and a research facility which, thanks to the fast neutron spectrum, makes it attractive for fuel and material development and testing of some special devices or other research works.

The three respective nuclear research institutes of the Central European region (ÚJV, Rež, Czech Republic, MTA EK, Budapest, Hungary, and VÚJE, a.s., Trnava, Slovakia) agreed in 2010 to start a joint project aiming at the preparation of the basic documents in order to form the 


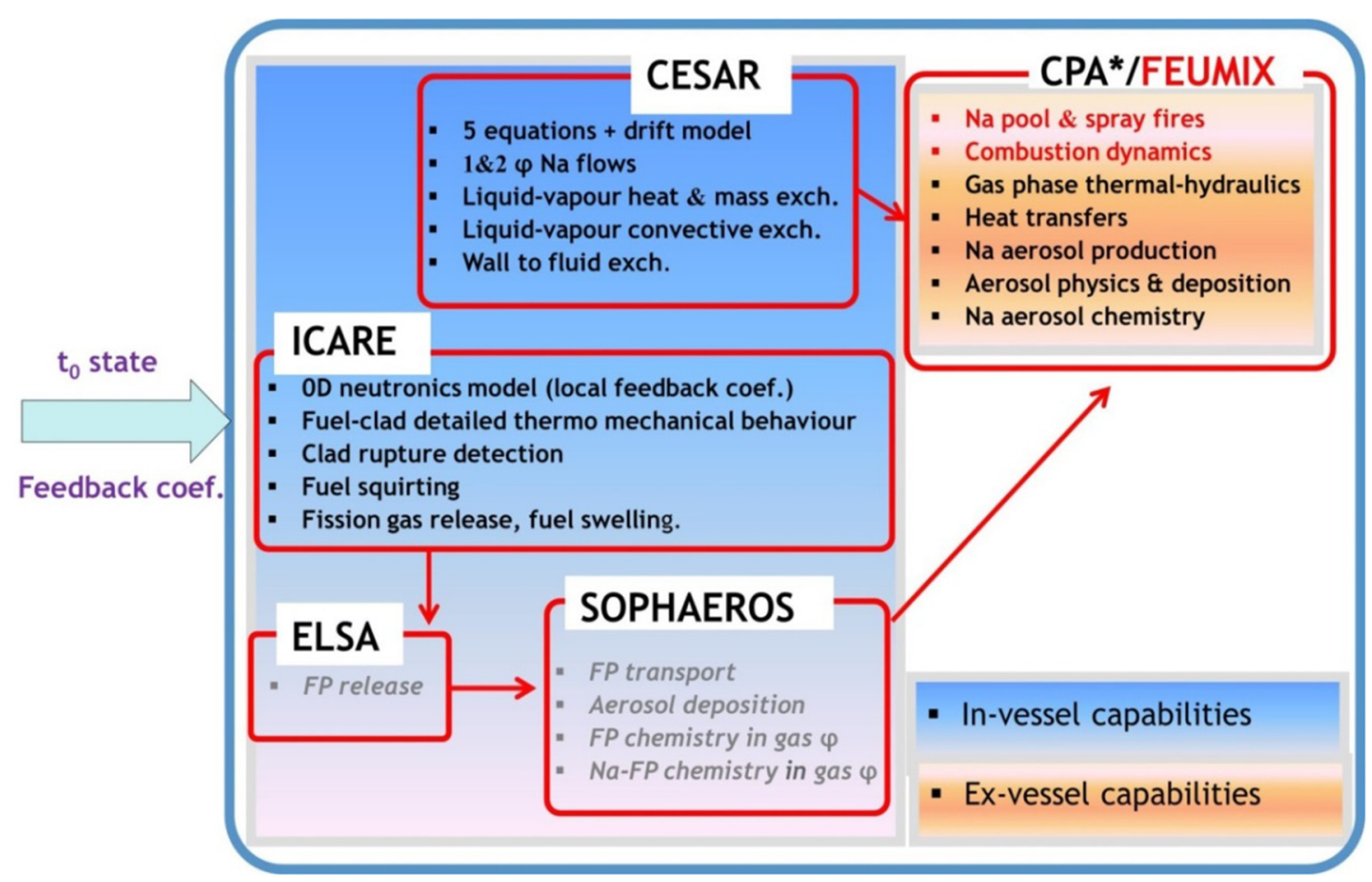

Fig. 7. ASTEC-Na calculation scheme and modelling capabilities.

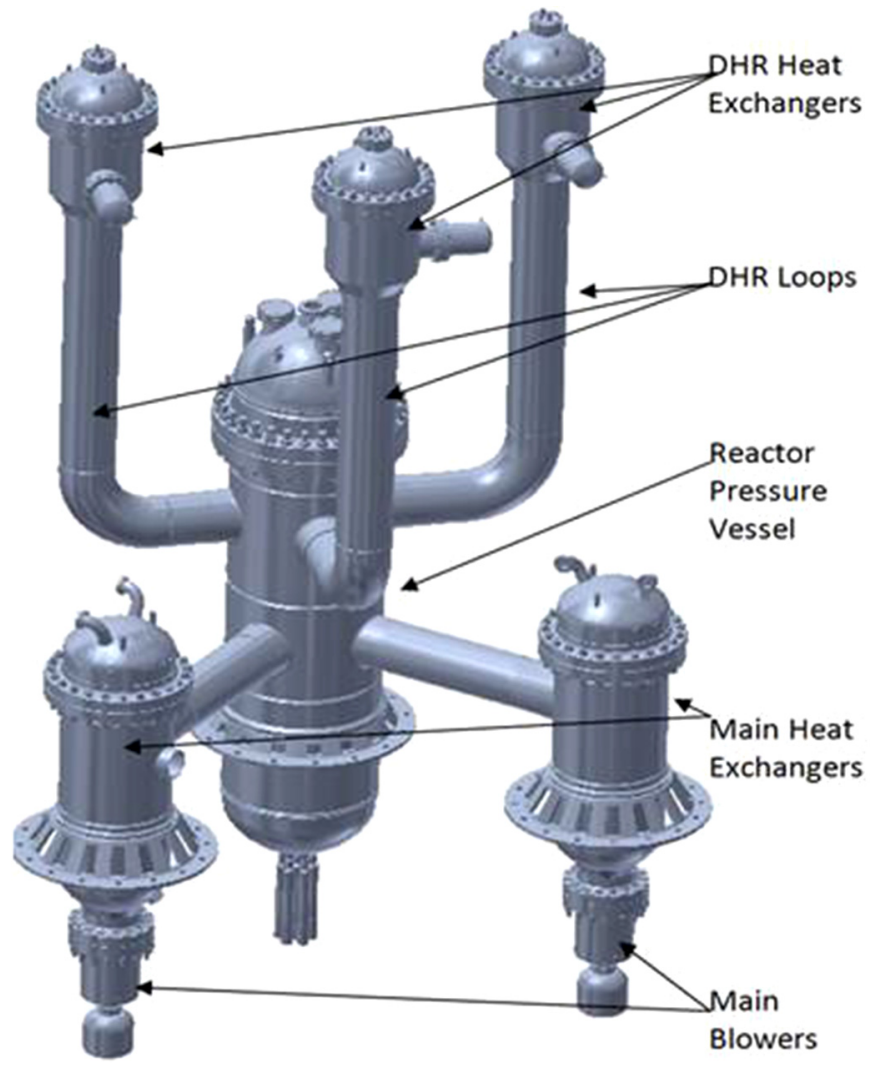

Fig. 8. Schematic drawing of the ALLEGRO Reactor (courtesy of Petr Darilek, VUJE). basis for a later decision on the construction and operation of the ALLEGRO gas cooled fast reactor in one of the countries. CEA, France, supports this effort by various means, especially by transferring the documents of the earlier design efforts (under appropriate Non-Disclosure Agreements) to the project participants. NCBJ, S wierk, Poland, joined the project in 2012, i.e. ALLEGRO is supported in all the four Visegrad-4 (V4) countries. The project ALLIANCE has been launched in 2012 by the nine member organizations (see Tab. 1).

\subsection{Key objective}

The aim of the project ALLIANCE was to continue the elaboration of basic documents needed for high level decisions and licencing of ALLEGRO. The ALLIANCE project [5-7] focused on the preparatory phase for developing the ALLEGRO gas cooled fast reactor demonstrator. The main nuclear parameters (like power density, burnup etc.) would be similar to those of the planned 2400 MWth power GFR. The core built up from the initial fuel type will be replaced by a core of ceramic fuel for the second half of ALLEGRO operation. Safety analysis performed within the previous EU GoFastR project covered the consequences of most initiating events and most of the ALLEGRO relevant issues were analysed. Safety principles of the ALLEGRO reactor will be based on the WENRA requirements and the study of GIF [8], added to the actual national safety rules of the hosting country. Moreover, in formulating siting requirements 
and requirements concerning the design to reduce the impact of external hazards, the results of the European stress tests following the Fukushima events were applied. Nevertheless the current design of ALLEGRO does not fully satisfy these requirements. One of the main reasons is that the safety margin of the stainless steel cladded mixed oxide (MOX) fuel chosen for the initial ALLEGRO core of 75 MWth power is rather low and cannot provide the necessary protection against core melting after a Fukushima-type accident (though the margin is acceptably large concerning Design Basis Accidents, i.e. accidents which may occur with a very low but not negligible probability).

\subsection{Key results}

A new strategy for developing the ALLEGRO reactor was prepared, and accepted by the Partners in 2015. The main components of this strategy are: (a) to reduce ALLEGRO power from $75 \mathrm{MW}$ th to $10 \mathrm{MWth}$ and to find the optimum core configuration (switch from MOX to $\mathrm{UO}_{2}$ ); (b) to optimize nitrogen injection (launch time, duration) and the backup pressure in guard containment; (c) to increase main blowers inertia to avoid short term peak temperature for the loss of coolant accident + blackout case and/or to develop a design with a gas turbine in the secondary side coupled to the primary blowers (this is the solution also advised for GFR).

A new systematic Roadmap was prepared to cover all design, safety and experimental aspects of ALLEGRO development.

The ALLEGRO consortium is represented by V4G4 Centre for Excellence, a legal entity registered in Slovakia. The main goal of V4G4 is to establish R\&D facilities to investigate fuel development issues, helium technology related problems, issues related to structural materials and to construct a non-nuclear 1:1 mock-up of ALLEGRO.

The Realisation Phase of the "ALLEGRO Project" will be started whenever the objectives of the Preparatory Phase are reached, approximately in 2025 . The realisation phase will include the preparation of the basic design, licensing (site permit, construction license, etc.), construction, operation and decommissioning of the ALLEGRO reactor.

As ALLEGRO will be a result of a joint effort on the regional (or even European) level, an international consortium should be formed to finance the entire project. The desired and potentially possible governance structure applicable in the Realisation Phase was discussed within the ALLEGRO project almost from the very beginning. It was found that the existing EU structures (e.g. "ERIC European Research Infrastructure Consortium") are not applicable as they are appropriate only for infrastructures used for basic research and they practically exclude the joint financing by governments and the industry. In case of nuclear development infrastructures the contribution from both sides is absolutely needed. The different governance models were discussed in detail in the project deliverables.

\subsection{Recommendations for the future}

The Design and Safety Roadmap was elaborated which consists of about 80 tasks in order to elaborate a new conceptual design with satisfactory safety features by 2025 . A pre-conceptual design will be prepared and discussed on the European level by 2020. The Roadmap clearly fixes the achievements needed for the pre-conceptual design and the conceptual design by tasks. Leading and participating member organisations are declared for each task. The manpower needed and eventual investment costs are also estimated per task. The first version of the ResearchDevelopment-Qualification Roadmap is also prepared. It consists of those experimental tasks which are necessary to complete in order to ensure a sound basis for the design.

One of the main challenges of the ALLEGRO design is associated with final resolution of the emergency decay heat removal from the core. This problem is a key issue for feasibility and safety acceptance of the GFR. To continue with development of the ALLEGRO GFR demonstrator design, complex set of tools is necessary, allowing reliable simulation of both operation and safety relevant events, up to severe accidents.

\section{JASMIN: Joint Advanced Severe accidents Modelling and Integration for $\mathrm{Na}$-cooled fast neutron reactors}

The project was launched in 2011 in support of both the ESNII roadmap and the Deployment Strategy of SNETP for the enhancement of Sodium-cooled Fast neutron Reactors (SFR) safety through the development of new capabilities to simulate innovative reactor designs [9]. The project was focussed on the primary phase of SFR core disruptive accidents, considered as the overture to larger scale core destruction. However, the code integrated features, which represents a good opportunity for simulating in a single code what is generally simulated in separate codes, were also considered through the in-containment source term modelling.

\subsection{Key objectives}

The project aimed at enhancing the current capability of analysis of severe accidents in SFRs by developing a new European simulation code, ASTEC-Na from the existing ASTEC platform developed by IRSN and GRS for LWRs. It was motivated by the need for new simulation tools with updated models, extended modelling scope and flexible platforms in replacement of the current available codes for SFR safety studies developed in the 1980s.

Then, it was intended to provide ASTEC-Na with:

- improved physical models (accounting for recent LWR and SFR research);

- a modern architecture and a high flexibility to ease its coupling with other tools and the accounting for innovative reactor designs;

- extended capabilities to evaluate the consequences of unprotected accidents on materials relocation and fission products and aerosols behaviour, once released.

Most important activities consisted in the development of new models and in their verification upon experimental data and through code benchmarks. 


\subsection{Key results}

\subsubsection{ASTEC-Na model development}

The three ASTEC-Na modules that focussed on the modelling efforts were CESAR, ICARE-SFR and CPA*. The final in-vessel and ex-vessel modelling capabilities listing the models that were developed are displayed in Figure 7. The ICARE module development particularly benefited from accurate fuel thermomechanical and fission gas models issued from $\mathrm{SCANAIR}^{1}$ for describing the pin behaviour during accidental transients which makes it very promising for assessing future SFR designs [9]. A highly flexible point-kinetics model was also implemented with the possibility to use time-dependent reactivity coefficient provided by neutron physics codes [10]. The in-containment source term modelling in $\mathrm{CPA}^{*}$ was focused on the Na-particle generation from pool fires and their chemical ageing. Other source term issue (like fission product scrubbing in Na pools, etc.) was left out. Late incorporation of the FEUMIX module, simulating sodium pool \& spray combustion, greatly enhance the code capabilities but still source term modelling in ASTEC-Na needs to be extended to the missing models.

\subsubsection{ASTEC-Na model verification and validation}

The CESAR thermos-hydraulic module, where the models developed most, pointed out good performances (i.e. boiling onset) for the single phase where the quality of ASTEC-Na results were found similar to what exhibited by more mature codes. For two-phase thermal-hydraulics, the pressure drop calculated by the 5 -equations model was generally too large and some deviations were found in the calculation of the two-phase front radial propagation inherent to the 2D axial-symmetric model. In ICARE, though the RIA model showed its capability to reproduce the dynamics of the physical phenomena (i.e. internal pressure built-up, gap closure, clad straining, etc.), some deviations from data trends during $\mathrm{PCMI}^{2}$ (i.e. axial fuel expansion, clad deformation) were observed that could prevent from an adequate molten fuel pressurization and clad failure calculation. The mechanistically based approach for fission gas simulation (requiring data not necessary available within SFR conditions) prevent from a conclusive RIA model validation.

The point kinetics model was found reliable to calculate the power evolution in a pool-type SFR during transients till the flux shape is not excessively perturbed. The validity of the model up to hexcan failure that depend on the material relocation and thus on the transient might be overcome, thanks to the ability of ASTEC-Na to use timedependent reactivity coefficients but will require performing a lot of iterations (to have adequate coefficients for a time period, the state of the core during this time period has to be known).

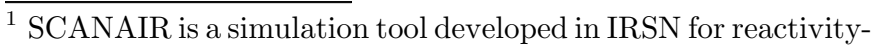
initiated accident (RIA) in LWRs.

${ }^{2}$ PCMI : Pellet-Clad-Mechanical-Interaction.
}

The verification of in-containment source term modelling in CPA* was not fully conclusive as key phenomena remained described by heavily parameterized models. However, the deviations from data trends, in airborne concentration of aerosols and their chemical compositions, highlighted a need for further review and extension of the implemented models. Code benchmarking could not help as ASTEC-Na was at the forefront of in-containment source term modelling.

\subsection{Recommendations for the future}

The ASTEC-Na tool, though offering great opportunities was still far from being mature at the end of the project The SWOT analysis performed in analysing the code weaknesses and threats allowed to point out the priorities in future development of the missing models and, beyond ASTEC-Na, to make some key recommendations for any forthcoming development and validation of a safety analytical tool:

- extend the validation of prototypic MOX fuel thermosmechanical and fission gas models to the high temperature domain covered in SFR transients;

- perform further analytical work on in-containment and in-vessel fission product behaviour to alleviate the scarcity of experimental data in the open literature.

As for ASTEC-Na, the development of an interface with a fuel irradiation and a neutron physics codes to minimize as far as possible the user work was strongly recommended and the continuation of the sensitivity studies on the RIA model key parameter warmly advised.

\section{ESNII Plus: Preparing ESNII for HORIZON 2020}

\subsection{Key objective}

The aim of this four-year cross-cutting project was to develop a broad strategic approach to advanced fission systems in Europe in support of the European Sustainable Industrial Initiative (ESNII) within the SET-Plan. The project involved private and public stakeholders, including industry, research and academic communities (see Tab. 1).

\subsection{Key results}

6.2.1 Organisation of ESNII to capitalise on opportunities in Horizon 2020 and beyond

Ways to coordinate the work of ESNII between EC and the national R\&D programmes were analysed. Central to this coordination is establishing the funding mechanisms that can be used to gain maximum leverage for funding obtained from the EC's Framework Programmes and for the Member State programmes.

\subsubsection{Future financial and legal models for ESNII}

Three challenges were identified:

- funding ESNII and SNETP. This is of the order of $\mathrm{k} €$ per partner, obtained from member organisations 
combined with Euratom grants (FP7 and Horizon 2020);

- funding the R\&D carried out on ESNII systems. This is of the order of $M €$, and is obtained from Member State national programmes and Euratom grants (Horizon 2020);

- funding design and construction of the ESNII demonstrators. This is of the order of $\mathrm{G} €$ and must be obtained from Member State national programmes.

\subsubsection{Strategic Roadmapping}

The aim of the task was to facilitate and define areas for joint programming between national actors, Member States and the EU. This task hence served as a first benchmarking exercise of joint proposals with variable common objectives and partnerships for Horizon $2020 \mathrm{EU}$ programmes. A workshop was organised and the following topics were identified: MOX Fuel, Austenitic and Ferritic-Martensitic Materials, In-core Instrumentation and RCC-MRX code.

\subsubsection{Support to facilities development}

Functional specifications of the $\mathrm{R} \& \mathrm{D}$ facilities related to SFR, LFR and GFR were identified with particular attention to the specificities and the unresolved issues. The availability and capabilities of irradiation infrastructure in Europe were reviewed in order to support the material and fuel development.

\subsubsection{Siting and licensing requirements for the new generation of fast reactors}

The specific requirements for licensing Generation-IV reactors are currently not explicitly included in the existing legal framework at the national level, even if there are plans or intentions to modify the legislations to improve the nuclear safety and to address the new reactor generation development. In order to survey the requirements and recommendations that may be used in the process of licensing Generation-IV systems, by capturing and integrating the international experience, an overview on the existing standards and recommendations (WENRA, GIF, EUR, CORDEL, MDEP and IAEA documents), with the consideration of Fukushima lessons learnt was performed. The conclusions drawn could be found in [11].

\subsubsection{Prospective analysis of supply chain}

Fast reactors, selected at European level as next generation Nuclear Energy Systems, pose undeniable challenges from a technological point of view. In order to support the foreseen deployment strategy, a survey of the existing supply chain has been thoroughly carried out in terms of its capabilities and potentialities with respect to Fast Reactors needs. The identified challenges of the EU nuclear industry with respect to Fast Reactors can be found in [12].

\subsubsection{Potential of small modular fast reactors}

Although the "economy of scale" was privileged as soon as nuclear was considered for civil applications, exceptions are represented by installations in remote regions or by specific technologies fitting in the small to medium power range. Opportunities offered by SMR based on fast reactors technologies were analysed, with a particular focus on LFR and the EU context. Two main potential applications were identified: installations of SMRs having power in the order of $100 \mathrm{MWe}$ for the compensation of renewables, or multi-units sites with a total power in the range 350-700 MWe for the replacement of fossil fuel power plants and the supply of process heat to industrial clusters.

\subsubsection{Potential of cogeneration fast reactors}

The additional opportunity of fast reactors designed for cogeneration applications (i.e., production of electricity and process heat) is made possible by the elevated temperatures characterizing the primary circuit of such reactors, compared to traditional LWRs. A state-of-theart overview on the EU cogeneration market with emphasis on opportunities for fast reactors was complemented by technical recommendations and by a top down cost estimate for an LFR system in a cogeneration application.

\subsubsection{Core physics}

Benchmarking activities of neutronic codes used in Europe and recommendations for their application to the different advanced concepts were performed. Main safety parameters of the three EU demonstrators were calculated with the main codes used in Europe. R\&D needs to improve the core safety were identified.

\subsubsection{Fuel}

MOX fuel properties catalogue was updated through additional measurements performed during the project on samples previously irradiated in European reactors. The effect of burn-up on thermal conductivity was, for the first time, measured on MOX fuel for fast reactors with high $\mathrm{Pu}$ content.

\subsubsection{Seismic behaviour}

The work focused on the modelling and analysis of the behaviour of the demonstrators by implementing seismic isolators including experimental verifications proving their efficiency in accidental conditions.

\subsubsection{Instrumentation}

Instrumentation and measurement techniques relevant to safety and in service inspection and repair were developed related to fuel cladding failure detection, coolant chemistry, thermal hydraulics characterisation and in-service inspection and repair.

\subsection{Recommendations for the future}

- ESNII shall continue organizing the EU R\&D on sustainable nuclear energy systems. Coordination with national member states programs needs to be encouraged. 
- The facilities for developing experimental programs shall be preserved and stronger cooperation facilitated to avoid duplications and improve budget utilization.

- A regulatory framework for Generation-IV reactors has to be built by countries interested in Generation-IV systems deployment to develop and maintain the competences for licensing process. The documents of IAEA, WENRA, NEA and EUR may be used in the process of developing national Generation-IV systems licensing requirements.

- Concerning the industrial supply chain, further specifications on Generation-IV specific components will be needed to verify if there are suppliers for them.

- Possible contribution of fast neutron systems to implementation of SMRs in Europe should be further investigated.

- In the core physics area, R\&D must be pursued to improve the safety.

- Measurements of MOX fuel properties using existing and future irradiation experiments, in particular those having an important impact on safety must be continued.

- Seismic devices and the corresponding modelling have to be encouraged for future projects of demonstrators.

- Competences in instrumentation must be preserved in some key European laboratories to support the safe operation of the nuclear installations.

\section{VINCO: Visegrad Initiative for Nuclear COoperation}

\subsection{Key objective}

Project VINCO (Visegrad Initiative for Nuclear COoperation) was Coordination and Support Action (CSA) carried out jointly by Visegrad countries (Czech Republic, Hungary, Slovakia and Poland) and France. Main objective of the VINCO project was to establish a cooperation network in Visegrad Group and France focused on studies of gas-cooled reactor technology, mainly Gas-cooled Fast Reactors (GFR). This Action complements already established V4G4 Centre of Excellence Association and represents the next stage of capacity building in nuclear technologies in Central European countries, focused mainly on ALLEGRO Project (see Fig. 8). Taking into account that development of a new nuclear technology becomes too complex and too costly for small and medium-sized countries the need of international cooperation becomes obvious. Visegrad countries decided thus to join their efforts and develop complementary specializations in participating countries, namely, reactor design and safety analyses in Slovakia, helium technology in Czech Republic, fuel studies in Hungary and material research in Poland. This group is completed by France, which started already studies on gas-cooled reactors, however, mainly due to current focus on sodium technology, had to slow down studies on GFRs. However, significant knowledge has been gathered earlier in French CEA, therefore its participation in further studies carried out in V4 countries is fully justified and beneficial for the project.
Main objectives of the VINCO project were thus:

- development of the principles of cooperation and rules of access to existing and planned infrastructure;

- identification of the specific objectives of the R\&D activities in the cooperating countries;

- description and analysis of the existing research, training and educational equipment and capabilities;

- determination of the investment priorities in cooperating countries; and

- setting up of joint research, educational and training projects.

A close cooperation with CEA, France ensured better description of the investments needed in Visegrad Region, tightening of pan-European cooperation and strengthening of the role of V4 countries, helping them to evolve from users to the suppliers of R\&D capabilities in nuclear technologies. A major expected impact of the project would be setting up of a distributed regional research centre specialized in nuclear technologies needed to develop Generation-IV reactors and to improve safe operation of existing and planned Nuclear Power Plants in the region.

\subsection{Key results}

Activities carried out in the frames of the VINCO project allowed to strengthen the links between the partners, establish running cooperation, especially in the field of simulation capabilities in participating institutions, initiate common educational and training actions and exchange the practices of experimental works in hot cell laboratories. Financial and legal framework analysis in V4 countries carried out within the project helped to identify the possible international cooperation schemes in V4 countries. Mutual learning and exchange of scientific staff between the laboratories took place, mainly in form of benchmark learning exercises on both, the neutronic and the thermohydraulic analyses and were devoted to the development of input models as well as the efficient use of various calculation tools utilized by different users. Several joint events were organized, such as School, workshops and exchange visits. An important part of the project was related to educational issues. Database of (nuclear) Educational Resources has been prepared and a brochure on Generation-IV technology prepared and printed. Finally, communication campaigns were organized to provide the information about nuclear technology for a broader public and establish contact with decision makers in the V4 Region.

\subsection{Recommendations for the future}

Recommendation for future actions constituted an important part of VINCO project activities. Main conclusion was that cooperation through the international agreement would bring advantages in the form of reaching of the critical mass required for such a project, clearly defined structure, competitions and responsibility. An obstacle can be politically and procedurally demanding scenario, as the wording of such agreement should be supported by a broadpolitical agreement of all countries. The ALLEGRO Education and Research Centre (ALLEGRO ERC) was 
evaluated as the most promising scheme of cooperation for the development of the GFR technology and generally for the development of any Generation-IV nuclear system technology after 2020. The Centre (possibly a part of ESFRI Roadmap) can integrate existing scientific and research resources of V4 countries, both human and technical, aiming the EU to keep up with other leading teams around the world in developing advanced nuclear power sources, with focus to GFR. The integrating aim of the ALLEGRO ERC is to prove feasibility and to provide sound basis for design of industrial scale nuclear GFR demonstrator ALLEGRO.

A long-term expected impact of the project is the strengthening of inter-regional cooperation of V4 countries in nuclear technologies and related educational activities by sharing available infrastructures, expertise, training and educational capabilities. Specialization and exchange of information should allow for the acquisition of the stateof-the-art equipment answering the common needs of European research institutions related to the development of Generation-IV of nuclear reactors.

After completion of the project we may state that the main lines of the expected project impact remain valid. Moreover, VINCO project helped us to identify new objectives for collaboration within V4 countries, namely, development of High Temperature Gas-cooled Reactor (HTR) technology, a topic especially important in Poland. $\mathrm{HTR}$ reactors may produce steam at $550{ }^{\circ} \mathrm{C}$, which is necessary for chemical industry and may constitute a necessary step in the implementation of more demanding GFR technology. These activities will be carried out in the frames of NOMATEN Centre of Excellence established in National Centre for Nuclear Research in close collaboration with strategic partners: CEA France and VTT Finland, which recently has been approved by the European Teaming for Excellence program constituting a new research quality in V4 countries.

\section{SESAME: Thermal hydraulics simulations and experiments for the safety assessment of metal cooled reactors}

\subsection{Key objectives}

The thermal-hydraulics is recognized as one of the key scientific subjects in the design and safety analysis of liquid metal cooled reactors [13]. SESAME project focuses on prenormative, fundamental, safety-related, challenges for the four liquid-metal fast reactor systems (ASTRID, ALFRED, MYRRHA, and SEALER) presented in Section 1 (see Fig. 1) with the following objectives:

- development and validation of advanced numerical approaches for the design and safety evaluation of advanced reactors;

- achievement of a new or extended validation base by creation of new reference data;

- establishment of best practice guidelines, Verification \& Validation methodologies, and uncertainty quantification methods for liquid metal fast reactor thermal hydraulics.
The goal is to improve the safety of liquid metal fast reactors by making available new safety related experimental results and improved numerical approaches. These will allow system designers to improve the safety relevant equipment leading to enhanced safety standards and culture. Due to the fundamental and generic nature of SESAME, developments will be of relevance also for the safety assessment of contemporary LWRs.

\subsection{Key results}

\subsubsection{Liquid metal heat transfer}

A fundamental issue is the modelling of the turbulent heat transfer over the complete range from natural, mixed and convection to forced convection regimes. Current engineering tools apply statistical turbulence closures and adopt the concept of the turbulent Prandtl number based on the Reynolds analogy. This analogy is no more applicable for liquid metals, and robust engineering turbulence models are needed. Within the SESAME project, the main focus was the extension of the validation base for mixed and natural convection regimes and for geometrically complex cases, together with further development and implementation of selected promising models in widely used engineering codes.

\subsubsection{Core thermal hydraulics}

Although experiments in liquid metal are being carried out in the European context on wire-wrapped fuel assemblies and to a lesser extent on fuel assemblies with grid spacers, the data to be retrieved from those experiments will be limited to pressure drops and the thermal field and will not include detailed information on the flow field. To derive reference data for the flow field in wire wrapped fuel assemblies, a combination of experimental data and reference high fidelity numerical simulations was set-up. Such need was not only recognized in Europe, but also in the US. A collaboration was established between the European and US partners allowing to maximize the benefits of both validation campaigns and to close the gap in the validation process of wire wrapped fuel assemblies.

Missing data for spacer-grid fuel assembly design were also produced by performing experiments in a liquid metal rod bundle. Such experiments were performed for grid spacers without blockages and with blockages and were accompanied by CFD simulations.

\subsubsection{Pool thermal hydraulics}

Although it is recognized that pool thermal-hydraulics as such is highly design dependent, the development and validation of modelling approaches for pool thermalhydraulics is not. In order to improve the validation base, liquid metal experiments were performed at different scales. Firstly, an experiment in the TALL-3D facility which includes a small pool in which thermal stratification and mixing phenomena can be studied. Four large scale experiments have been performed in the CIRCE facility using the so-called ICE test section which has been instrumented such that relevant data for thermal 

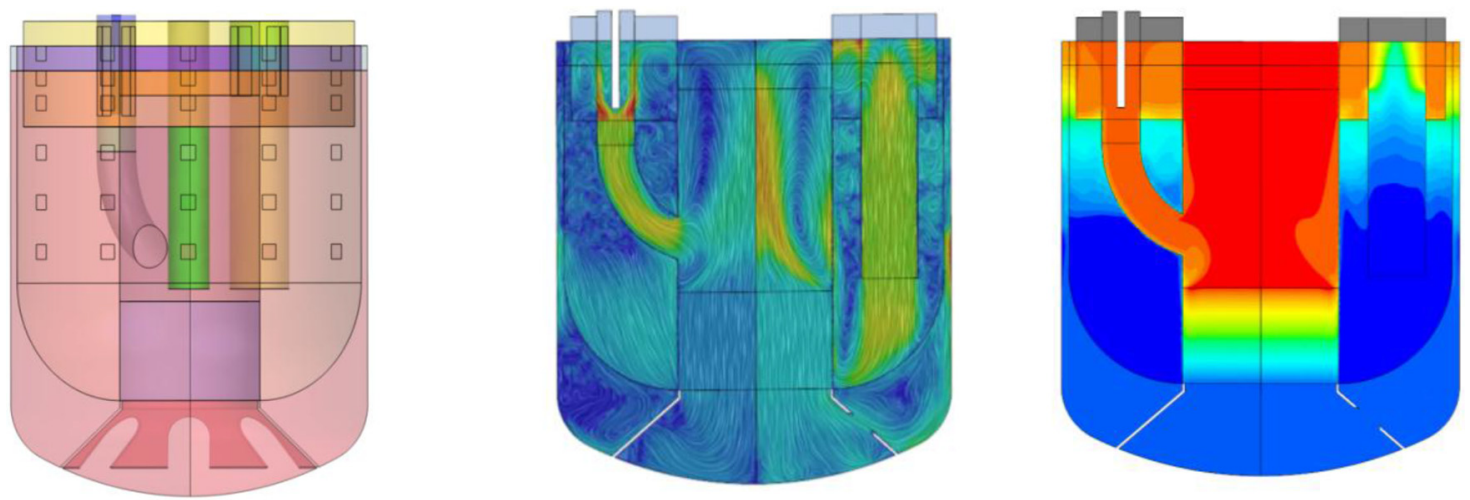

Fig. 9. CFD Model of ALFRED primary loop. (Courtesy of CRS4, SESAME Task 3.1.2).

stratification and flow patterns can be extracted. The ESCAPE facility, a scaled down mock-up of MYRRHA, is instrumented such that relevant data for thermal stratification and flow patterns can be extracted. In parallel, CFD approaches were developed for all facilities mentioned and validated using the experimental data. Finally, the validated CFD approaches were applied to the MYRRHA and ALFRED reactor design (see Fig. 9).

\subsubsection{System thermal hydraulics}

Traditionally, the analysis of nuclear system behaviour is performed using system thermal-hydraulics codes. Such analyses are validated using integral design specific experiments or reactor data from prototype, test, or demonstration reactors. In recent years, the traditional approach of using system thermal-hydraulic codes is supplemented with new multi-scale approaches in which system thermal hydraulics codes are coupled to detailed three-dimensional CFD approaches. SESAME project aimed at extending the validation base by providing reference data at different levels. The validation data were provided in loop scale by experiments in the NACIE-UP facility, focused on the multi-scale coupling of the behaviour in the fuel assemblies and the loop system. Scaling up, the CIRCE facility in the so-called HERO configuration is used to provide experimental validation data. Real reactor data were provided from the Phénix reactor end of life tests. This data allowed validation of the three-dimensional effects to a much larger extent than the natural circulation test data which were previously used. Finally, the approaches under development will be applied to the MYRRHA and ALFRED lead-cooled reactor designs.

\subsubsection{Guidelines and education}

One of the main goals of the SESAME project is the establishment of Best Practice Guidelines, Verification \& Validation methodologies, and Uncertainty Quantification methods. To this purpose work meetings have been organized in Stockholm (2016) in which the current practices and experiences of all partners and some invited experts from outside the project have been compared and discussed. With respect to education and training, a lecture series was organized in 2017 hosted by VKI in Belgium. During the lecture series, experts from the project disseminated their knowledge on experimental techniques and modelling approaches. The textbook [14] was published as one of the main deliverables to the nuclear liquid metal community at large. Finally, an international workshop on nuclear liquid metal thermal hydraulics was hosted by NRG in Petten, with more than 70 lectures, and participants from the entire world.

\subsection{Recommendations for the future}

SESAME project improved the safety of liquid metal fast reactors not only in Europe but also globally by making available new safety-related experimental results and improved numerical approaches. These outcomes will allow designers to improve the safety of their reactors, which will finally lead to an enhanced safety culture. For the future, it is recommended to keep the successful approach of SESAME in which experiments, modelling and simulations moved hand-in-hand. New projects, based on the outcomes of SESAME, would be implemented enlarging the community, strengthening the partnerships, improving the synergies, leading innovation, enhancing safety culture at the European and international level.

\section{SAMOFAR: a paradigm shift in reactor safety with the Molten Salt Fast Reactor}

The ultimate aim of nuclear energy research is to develop a nuclear reactor that is truly inherently safe and that produces no nuclear waste other than fission products. The Molten Salt Fast Reactor (MSFR) has the potential to reach these goals. The most characteristic property of a molten salt reactor is the liquid fuel, which provides excellent options for reactivity feedback and decay heat removal. Furthermore, the continuous recycling of the fuel salt enables one to design a reactor either as a breeder reactor with in situ recycling of all actinides, or as a burner capable of incinerating the actinide waste from other reactor types. 

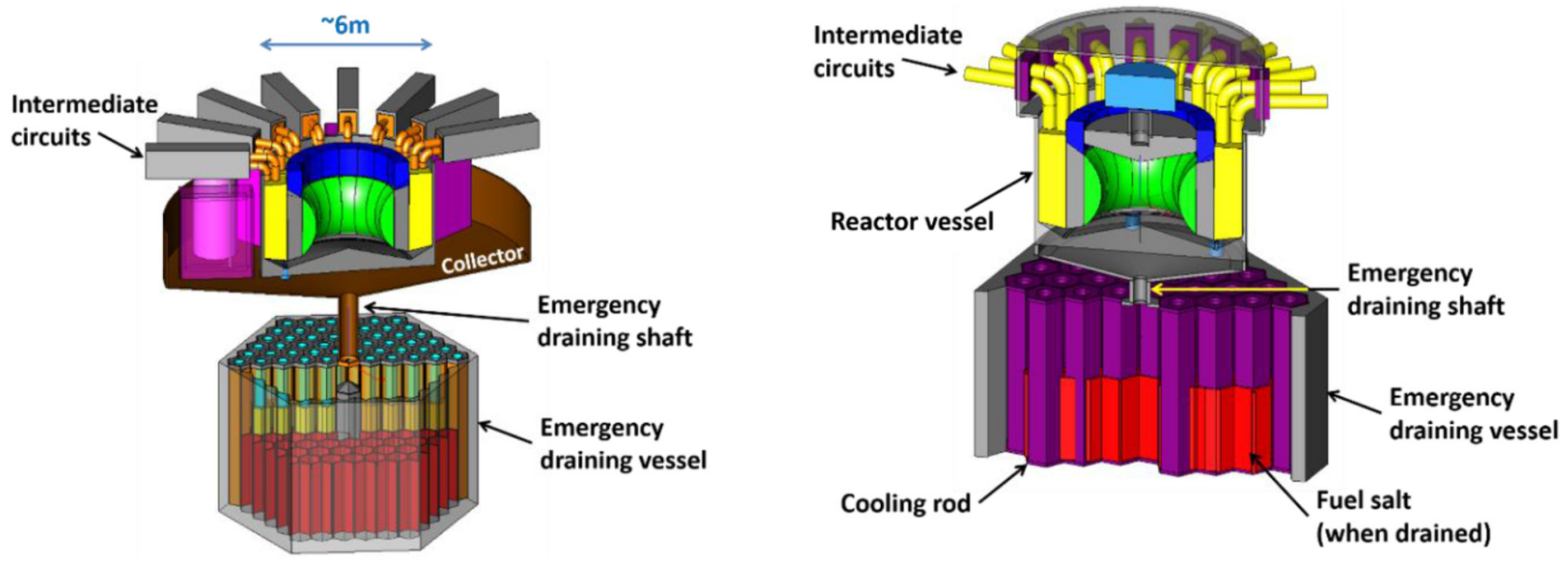

Fig. 10. Schematic design of the primary circuit of the MSFR showing the reactor vessel and emergency draining system for the fuel salt.

\subsection{Key objectives}

The grand technical objective of the SAMOFAR project is to prove the innovative safety concepts of the MSFR by advanced experimental and numerical techniques, and to deliver a breakthrough in nuclear safety and optimal waste management. This objective has been split in four sub-objectives:

- delivering the experimental proof of concept of the unique safety features of the MSFR;

- providing a safety assessment of the MSFR for both the reactor and the chemical plant;

- updating the conceptual design of the MSFR;

- creating momentum among key stakeholders.

Besides the Work Package (WP) on project management, the SAMOFAR project contains six specialized parts. WP1 deals with the integral safety assessment and the overall reactor design (see Fig. 10) including the chemical operation plant. WP2 determines experimentally all safety-related data of the fuel salt. WP3 investigates experimentally and numerically the natural circulation dynamics of the fuel salt in the primary vessel and emergency drain tanks, and the behaviour of the salt in the freeze plugs during a drain transient. WP4 assesses numerically the accident scenarios identified in WP1, which include the normal operation transients and the off-normal accident scenarios. WP5 assesses experimentally and numerically the safety aspects of the chemical extraction processes, and the interaction between the chemical plant and the reactor. WP6 covers the dissemination and exploitation of knowledge and results, e.g. by education and training of young scientists.

SAMOFAR is the latest MSR-related project in a successful series (MOST, ALISIA, EVOL) and started in August 2015. The SAMOFAR consortium consists of 11 partners from the EU, Switzerland and Mexico, each providing a specific own contribution. Besides the partners' contribution, also observers participate to the project.

\subsection{Key results}

In WP1, the design of the MSFR including the emergency draining system has been updated and assessed by a panel of experts. A plant simulator has been developed and is now being used to define reactor control strategies and procedures for the various operation modes of the MSFR, such as full power operation, load-following, start-up and shut-down. A risk assessment methodology has been developed based on the Integrated Safety Assessment Methodology, which will lead to "built-in" safety at the early design stages. Other risk analysis methods have been applied to the MSFR and have led to the identification of postulated initiating events and a list of relevant design key-points.

Test calculations with the MELCOR and ASTEC severe accident codes showed that these codes can most probably be used, but that some data need to be added. A special setup has been constructed for experimental studies of actinides in molten fluorides and for the synthesis of actinide fluorides. Experimental studies on the vaporization behaviour of the fuel salt revealed the retention properties at high temperature. It turns out that $\mathrm{CsF}$ remains fully dissolved in the salt, but that CsI needs further investigation. A test facility has been made to measure viscosity of salts based on ultra-sound methods. Finally the interaction of salt with water under the influence of gamma radiation has been investigated.

In WP3, the major experimental contributions in two large setups (DYNASTY and SWATH) have been prepared. For DYNASTY, numerical research has revealed flow instabilities in a natural circulation loop with a distributed heated salt. The DYNASTY facility is in operation to generate experimental data, which will be used for stability analysis and for the validation of numerical codes in WP4. The design and construction of the SWATH facility and the test sections in which the experiments will be carried out have been completed. SWATH uses a molten salt between $500^{\circ} \mathrm{C}$ and $700^{\circ} \mathrm{C}$ to perform thermal hydraulics measurements, including phase change phenomena and experiments on freeze plugs. 
In WP4, transient calculations based on the scenarios identified in WP1 will be performed based on leading-edge multi-physics codes including uncertainty propagation. Verification and validation of these code systems has been done via code-to-code comparison and by using the experimental data generated in WP3.

In WP5, the fuel salt processing scheme has been updated, and thermochemical calculations have revealed the transfer coefficients. This data has been used to calculate the radionuclide inventory at each stage using new software, as well as the radioactivity, the decay heat production and the shielding requirements. The behaviour of uranium and iodine in the salt has been investigated experimentally.

In WP6, a summer school has been organized with focus on the scientific fundamentals of fluid fuel reactors. Almost $90 \mathrm{MSc} / \mathrm{PhD}$ students and young professionals participated. The SAMOFAR website (http://www. SAMOFAR.eu) acts as the portal to reach the public and for information exchange and for archiving. The YouTube channel (http://samofar.eu/samofar-youtubechannel/) has been updated with lectures from the summer school and movies.

\subsection{Recommendations for the future}

The MSFR is a reactor design at low TR level with several points for improvement. To come to a realistic safety assessment of the reactor, a more detailed design is needed with better materials data (structural materials, fuel salt properties, etc), validated simulation models of the specific phenomena occurring in the MSFR, and reliable data on the performance of components and processes. These topics are subject of the new SAMOSAFER proposal that focuses, among others, on safety requirements and risk identification of molten salt reactors including the chemical processing plant; measurement and calculation of the fuel salt retention properties; evaluation of nuclide mobility and the resulting inventory in each compartment of the reactor including the chemical processing plant; modelling and simulation of phenomena needed for the safe confinement of fuel salt; modelling of heat removal processes, including radiation heat and other phenomena; reactor operation and control to assess normal operation and emergency operation; education and training of students, and dissemination and exploitation of our results.

\section{ESFR-SMART: European Sodium Fast Reactor Safety Measures Assessment and Research Tools}

\subsection{Key objectives}

To improve the public acceptance of the future nuclear power in Europe we have to demonstrate that the new reactors have significantly higher safety level compared to traditional reactors. The ESFR-SMART project [15] aims at enhancing further the safety of Generation-IV SFRs and in particular of the commercial-size European Sodium Fast
Reactor (ESFR) in accordance with the ESNII roadmap and in close cooperation with the ASTRID program. The project aims at 5 specific objectives:

- produce new experimental data in order to support calibration and validation of the computational tools for each defence-in-depth level;

- test and qualify new instrumentations in order to support their utilization in the reactor protection system;

- perform further calibration and validation of the computational tools for each defence-in-depth level in order to support safety assessments of Generation-IV SFRs, using the data produced in the project as well as selected legacy data;

- select, implement and assess new safety measures for the commercial-size ESFR, using the GIF methodologies, the FP7 CP-ESFR project legacy, the calibrated and validated codes and being in accordance with the update of the European and international safety frameworks taking into account the Fukushima accident;

- strengthen and link together new networks, in particular, the network of the European sodium facilities and the network of the European students working on the SFR technology.

Close interactions with the main European and international SFR stakeholders (GIF, ARDECo, ESNII and IAEA) via the Advisory Review Panel will enable reviews and recommendations on the project's progress as well as dissemination of the new knowledge created by the project. By addressing the industry, policy makers and general public, the project is expected to make a meaningful impact on economics, EU policy and society.

\subsection{Key results}

The project is currently close to the end of the second year and the key results obtained at the first phase of the project are summarised below [15].

\subsubsection{Proposal of new safety measures}

The key idea is to make a next step in developing the largepower (1500 MWe/3600 MWt) SFR concept, following up the "line" of the Superphenix 2 (SPX2), European Fast Reactor (EFR) and ESFR designs and using the set of the GIF objectives as a target. In particular:

- the ESFR core design modifications were aimed at improving the core map symmetry; optimizing the void effect; and facilitating the corium relocation toward the corium catcher;

- the ESFR system modifications were aimed at simplifying the overall design (see Fig. 11) and improving the safety functions: control of reactivity, heat removal from fuel, and confinement of the radioactive materials.

\subsubsection{Evaluation of core performance}

After the new core design was proposed the studies were launched to check how this core design will influence the neutronics and fuel performance. In particular: 


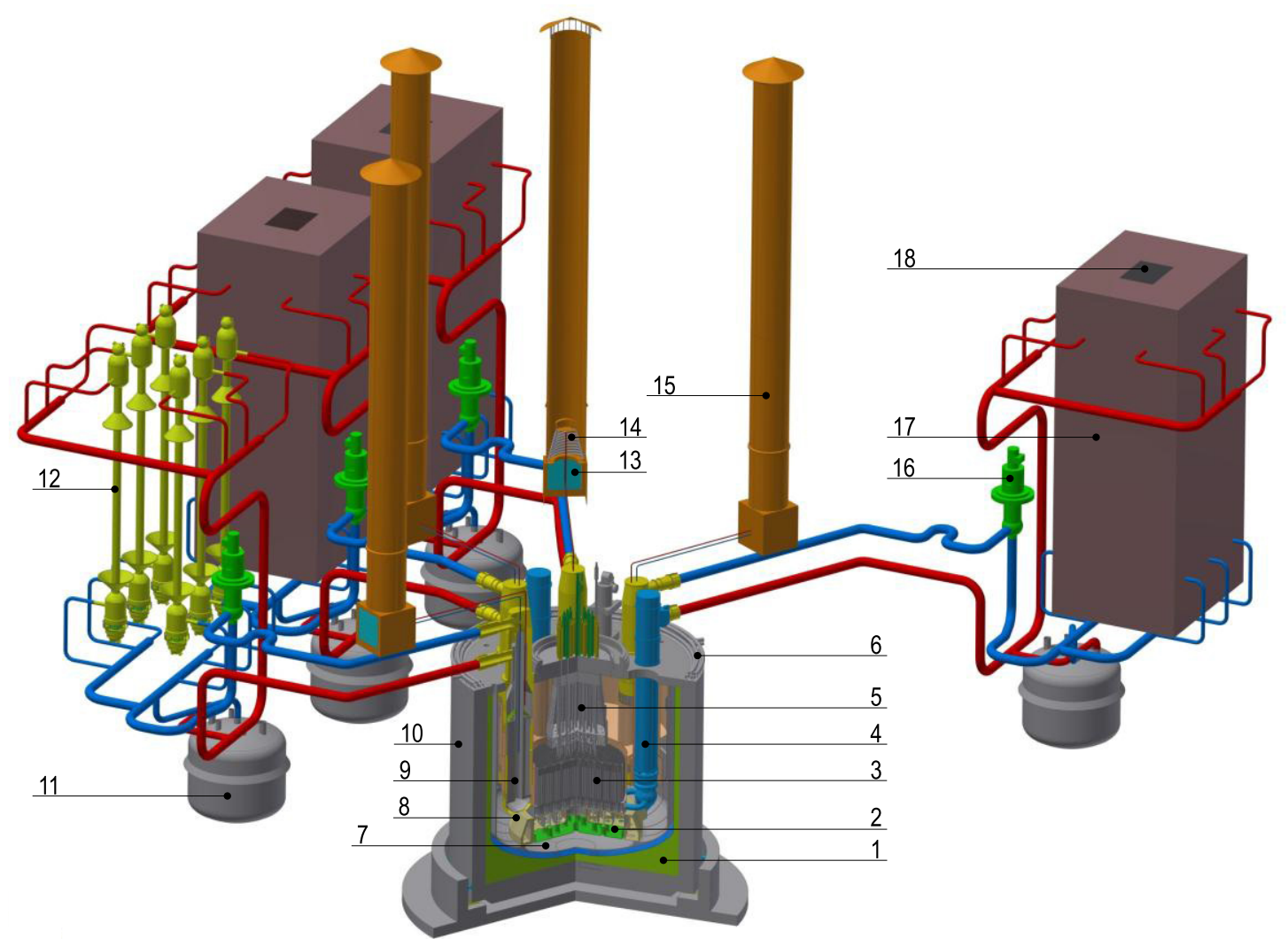

1: Insulation with steel liner
2: Core catcher
3: Core
4: Primary pump
5: Above-core structure
6: Pit cooling system (DHRS-3)

7: Main vessel

8: Strongback

9: IHX

10: Reactor pit

11: Secondary sodium tank

12: Steam generator
13: Window for air circulation (DHRS-1)

14: Sodium-air HX (DHRS-1)

15: Air chimney (DHRS-1)

16: Secondary pump

17: Casing of SGs (DHRS-2)

18: Window for air circulation (DHRS-2)

Fig. 11. General view of ESFR-SMART reactor.

- six-batch burnup calculations were performed using a Monte Carlo code and the core state specification at the End of Equilibrium Cycle were defined, including the 3D isotopic composition needed to calculate the reactivity coefficients and kinetics parameters as well as the 3D power distribution for the following-up thermal-hydraulic analysis;

- fuel performance for a typical cycle was analysed with a number of fuel performance codes and the gap heat conductance correlation was derived for the subsequent steady-state and transient thermal-hydraulic analyses.

\subsubsection{Benchmarking of codes}

One of the specific objectives of the project is to perform further calibration and validation of the computational tools for each defence-in-depth level. In particular:

- a new calculational benchmark has been proposed for the start-up core of the Superphénix (SPX) Sodium Fast Reactor based on open publications;

- a computational exercise on sodium boiling modelling was organized based on a KNS-37 sodium loop experiment featuring sodium boiling in pin-bundle geometries.

\subsubsection{Experimental programs}

Two specific objectives of the project address new experiments: (1) to produce new data to support calibration and validation of the computational tools for each defence-indepth level; (2) to test and qualify new instrumentations in order to support their utilization in the reactor protection system. In particular:

- new test on chugging boiling regime (CHUG) was launched to support the computational activities on analysis of the ESFR behaviour under sodium boiling conditions;

- new test on corium jet impingement (HAnSOLO) was started using a water-ice system as a model of the coriumcatcher system;

- safety rules were formulated for designing a new hightemperature sodium facility;

- Eddy-current flow meters (ECFM) was qualified for a positioning above the fuel assemblies in order to detect possible blockages of the sodium flow. 


\subsection{Recommendations for the future}

Since the project is only at the second year no recommendations for the future are provided.

\section{Conclusion}

The paper briefly presents nine Euratom projects started since late 2011 in support of the infrastructure and R\&D of the seven fast reactor systems.

The SARGEN IV project was the first opportunity to gather together various experts of fast reactors safety from TSOs, research institutes, utilities and universities. The project allowed very fruitful exchanges providing a synthesis on identification and ranking of the safety issues and the proposal for a harmonization of the safety assessment practices that could be used further for each of the concepts proposed by the ESNII. Beside showing how difficult it is to have a detailed safety assessment when the design of the reactor is not well defined, the SARGEN_IV project contributed to the harmonisation of the different methodologies, crucial for developing a consistent assessment platform which could be used effectively in the decision-making process and to make the different innovative reactor types publicly acceptable in Europe.

The SILER project demonstrated that the technology for the seismic isolation of nuclear facilities already exists and that the main components like isolators (in particular High Damping Rubber Bearings and Lead Rubber Bearings) and flexible joints for pipelines (even the more critical ones) are reliable enough to guarantee the safety of the plant, even in the case of beyond design events. SILER also confirmed the significant advantages given by seismic isolation, not only in terms of reduction of the seismic actions on the structure and most critical components, but also from the economical point of view, thanks to the possibility of standardizing the design of the reactor building, making it substantially independent of the seismicity of the construction site. Some activities of SILER continued in the ENSII Plus Project (see Sect. 6), regarding the design of the seismic isolation systems of the ASTRID and ALFRED reactors.

The ALLIANCE project is helping to realise the vision of a next-generation GFR in one of four central European countries during the next decade. Outcomes will help meet EU energy and climate targets.

The JASMIN project has fostered a collaborative work on the integral Beyond Design Basis Accident (BDBA) ASTEC-Na code development and validation. The project, relied on the PIRTs produced within the previous CP-ESFR FP7 project, capitalized the large amount of knowledge produced since 40 years in this field in the ASTEC-Na code development by collecting and sharing some past experimental program results, and disseminated it to end users. JASMIN end-products were the final version of the ASTEC-Na code and the associated validation experimental matrices. Both might be used in the future not only for $R \& D$ activities but also for industrial applications. Cross-cutting issues were also investigated and led to the conclusion that the sound bases of ASTEC-Na and the existing similarities with $\mathrm{Pb}$-cooled and $\mathrm{Pb}-\mathrm{Bi}$ reactors, turn it to be a good option to develop an ASTEC-LM (Liquid Metal) version.

The ESNII Plus project prepared the ESNII structuration and deployment strategy, to ensure efficient European coordinated research on Reactor Safety for the next generation of nuclear installations, linked with SNETP SRA priorities. To achieve the objectives of ESNII, the project coordinated and supported the preparatory phase of legal, administrative, financial and governance structuration, and ensured the review of the different advanced reactor solutions. At the same time, the project addressed the following technical cross-cutting areas:

- core physics benchmarking activities of neutronic codes used in Europe and recommendations for their application to the different advanced concepts. Identification of $\mathrm{R} \& \mathrm{D}$ needs to improve the core safety;

- fuel update of the MOX fuel properties catalogue through additional measurements performed during the project on samples previously irradiated in European reactors; - seismic behaviour, modelling and analysis of the behaviour of the demonstrators by implementing seismic isolators including experimental verifications;

- instrumentation development and measurement techniques relevant to safety and in service inspection and repair.

The VINCO project addresses one of the most important problems of the society: to find energy for future generations. Obviously, such a problem cannot be resolved by a small, C\&S action; however, VINCO contributes to its solving by building a research platform able to cope with one of the future concepts, gas-cooled nuclear reactors, in Visegrad countries.

Within the SESAME project, new analytical and simulation methods are being validated with reference data. Most of these reference data are based on experimental results and, when not feasible, are complemented or replaced by high fidelity simulation data (typically DNS or LES). As such, within these projects, experiments, high fidelity reference simulations and pragmatic engineering simulation will go hand-in-hand providing not only the international liquid metal fast reactor designers, but also the light water community with valuable new reference data and modelling approaches.

The progress in the SAMOFAR project till now, which is only very briefly summarized in this paper, contains significant results beyond current knowledge, both in the fields of safety assessment, Molten Salt Fast Reactor design, fuel salt data, experimental evaluation, numerical algorithms and modelling, and the synthesis of salts and coatings. Many results were published at scientific conferences, journals and other dissemination channels to increase the impact of the project. The inclusion of SAMOFAR related topics in the curricula of the university programs has contributed to the dissemination and to the education of students. The SAMOFAR project is scheduled to finish at July 31, 2019.

On one hand, the ESFR-SMART project continues the development of the European Sodium Fast Reactor 
concept following up the EFR and CP ESFR projects especially in terms of safety enhancement and design simplification. On the other hand, R\&D activities in support of the Sodium Fast Reactors in general are performed in terms of codes validation and calibration, new experiments and new instrumentation, support of sodium facilities and measurements of MOX fuel properties. The project is ongoing and scheduled to finish in August 2021.

Projects have received funding from the Euratom research and training programme under grant agreements No. 295446, 295485, 323295, 295803, 605172, 662136, 654935, 661891, 754501 .

\section{References}

1. SARGEN IV EC Project: Deliverable 2.5 Identification and ranking of the safety issues

2. SARGEN_IV EC Project: Deliverable 3.5 Proposal for a harmonization of the safety assessments practices

3. M. Forni, A. Poggianti, R. Scipinotti, A. Dusi, E. Manzoni, Seismic isolation of lead-cooled reactors: the European project SILER, Nucl. Eng. Technol. 46, 595 (2014)

4. M. Forni, A. Poggianti, R. Scipinotti, A. Dusi, E. Manzoni, M.G. Castellano, Seismic-Initiated event risk mitigation in LEad-cooled Reactors: Main results of the Siler Project, in SECED 2015 Conference: Earthquake Risk and Engineering towards a Resilient World, 9-10 July 2015, Cambridge, UK

5. A. Horvath, ALLIANCE - Preparation of ALLEGRO Implementing advanced nuclear in Central Europe, in FISA 2013, 8th European Conference on Euratom Research and Training in Reactor Systems, Vilnius, Lithuania, 14-17 October, 2013

6. B. Hatala, P. Darilek, R. Zajac, M. Lackova, ALLEGRO project, in Conference EUROSAFE 2015, Brussel, Belgium, November 2-3, 2015

7. J. Berka, T. Hlinčík, I. Víden, T. Hudský, J. Vít, The design and utilization of a high temperature helium loop and other facilities for the study of advanced gas-cooled reactors in the Czech Republic, Prog. Nucl. Energy 85, 156 (2015)

8. GIF/RSWG/2007/002, Basis for the safety approach for design \& assessment of Generation IV nuclear systems, 2007

9. S. Perez-Martin, W. Pfrang, N. Girault, L. Cloarec, L. Laborde, M. Buck, V. Matuzas, A. Flores, Y. Flores, P. Raison, A.L. Smith, N. Mozzani, F. Feria, L. Herranz, B. Farges, Development and assessment of ASTEC-Na fuel pin thermomechanical models performed in the European JASMIN project, Ann. Nucl. Energy 119, 454 (2018)

10. V. Matuzas, L. Ammirabile L. Cloarec, D. Lemasson, S. Perez-Martin, A. Ponomarev, Extension of ASTEC-Na capabilities for simulating reactivity effects in Na-cooled fast reactors, Ann. Nucl. Energy 119, 440 (2018)

11. M. Nitoi, J.-M. Carrere, Z. Hozer, L. Burgazzi, D. Gugiu, M. Farcasiu, M. Constantin, Siting and licensing requirements for GenIV demonstrators, ESNII Plus Deliverable D3.3.1, July 2017

12. M. Frignani et al., Status and perspectives of industrial supply chain for Fast Reactors, in Proc. of International Conference on Fast Reactors and Related Fuel Cycles: Next Generation Nuclear Systems for Sustainable Development (FR17), Yekaterinburg, Russia, 26-29 June 2017

13. F. Roelofs, K. Van Tichelen, M. Tarantino, European thermal-hydraulic progress for sodium and lead fast reactors, in The 17th International Topical Meeting on Nuclear Reactor Thermal Hydraulics (NURETH-17), Xi'an, China, September 2017

14. F. Roelofs, Thermal hydraulics aspects of liquid metal cooled nuclear reactors (Elsevier, Cambridge, 2019)

15. K. Mikityuk, E. Girardi, J. Krepel, E. Bubelis, E. Fridman, A. Rineiski, N. Girault, F. Payot, L. Buligins, G. Gerbeth, N. Chauvin, C. Latge, J. Guidez, Horizon-2020 ESFR-SMART project on SFR safety: status after first 15 months, in 27th International Conference on Nuclear Engineering ICONE27, Tsukuba International Congress Center, Tsukuba, Ibaraki, Japan, May 19-24, 2019

Cite this article as: Konstantin Mikityuk, Luca Ammirabile, Massimo Forni, Jacek Jagielski, Nathalie Girault, Akos Horvath, Jan-Leen Kloosterman, Mariano Tarantino, Alfredo Vasile, Review of Euratom projects on design, safety assessment, R\&D and licensing for ESNII/Gen-IV fast neutron systems, EPJ Nuclear Sci. Technol. 6, 36 (2020) 